\title{
В. В. Казаковская
}

Институт лингвистических исследований РАН

(Санкт-Петербург, Россия)

victory805@mail.ru

\section{Н. К. Онипенко *}

Институт русского языка им. В. В. Виноградова РАН

(Москва, Россия)

onipenko_n@mail.ru

\section{ФУНКЦИОНАЛЬНЫЕ ВОЗМОЖНОСТИ ВВОДНО-МОДАЛЬНЫХ СЛОВ В РЕЧИ ВЗРОСЛЫХ И ДЕТЕЙ}

Объектом исследования являются функции вводно-модальных слов в системно-языковом (синхрония vs. диахрония), дискурсивно-текстовом и онтолингвистическом аспектах. Вводные слова интерпретируются в связи с понятием модуса и моделью субъектной перспективы текста. Условием образования вводных слов признается появление в семантике лексемы эгоцентрической составляющей. Эгоцентрическая сущность таких единиц проявляется в ограничении личной парадигмы и закреплении за лексической единицей определенных вариантов субъектной перспективы, дискурсивная сущность - в возможности употребления в составе союзных скреп и во взаимодействии с союзами. Рассматриваются разные синтаксические позиции слов эпистемической семантики и текстовые функции вводных слов в третьеличном нарративе. В работе используются материалы НКРЯ (художественный нарратив), а также данные речевого онтогенеза, полученные лонгитюдным и срезовым методами. Они представлены расшифрованными и морфологически размеченными в соответствии с CHILDES аудио- и видеозаписями звучащей речи - раннего диалога «взрослый - ребенок», а также материалами устной и письменной речи подростков - учащихся 8-11 классов общеобразовательных школ России, дополненными анкетами, отражающими отношение современных тинейджеров к вводным словам.

Ключевые слова: синтаксис, коммуникативная грамматика, онтолингвистика, вводные слова, модус, эгоцентрическая лексика, парентетическая позиция.

\footnotetext{
* Исследование выполнено при поддержке РФФИ (проект № 18-012-00 263).
} 
1. Системное функционально-грамматическое описание вводных слов соединяет лексическую семантику, морфологию, синтаксис и анализ текста; устанавливает связи между типом модуса и набором языковых средств (лексических и синтаксических), предназначенных для выражения этого модуса [Золотова, Онипенко, Сидорова 2004: 279-310]; выявляет отношение различных по модусной семантике лексем к категории лица [Онипенко 2013]. Семантика вводных слов интерпретируется двумя терминами - «модальные» и «модусные». Первый термин используется в связи с тем, что часть вводных слов принадлежит к средствам выражения эпистемической модальности. При этом другую часть относят к метатекстовым средствам или к категории эвиденциальности [Падучева 2016]. Замена прилагательного «модальный» прилагательным «модусный» позволяет соединить все средства выражения точки зрения говорящего в один класс слов, что представляется перспективным для современной русистики.

Вводными называют слова (отдельные лексемы), словоформы, словосочетания (а в широком смысле и предикативные конструкции, в том числе союзные), которые, формально находясь в составе высказывания, не входят в его структуру, не вступают в синтаксические связи с членами этого предложения и выражают 1) отношение говорящего к содержанию и оформлению его высказывания; 2) источник информации, заключенной в высказывании; 3) поддержание контакта с адресатом и 4) место высказывания в линейной последовательности текста. Отличительными признаками вводных слов являются: 1) невозможность постановки вопроса; 2) возможность изъятия при сохранении синтаксической структуры предложения и его общего пропозиционального смысла; 3 ) ограничение словоизменительных возможностей слова (идиоматизация); 4) отсутствие закрепленной позиции по отношению к началу и концу предложения; 5) участие в актуальном членении предложения (как правило, в составе ремы); 6) особое интонационное выделение, оформляемое на письме парными пунктуационными знаками (чаще парной запятой); 7) способность взаимодействовать с союзными средствами связи или выступать как средство связи в составе сложного предложения. А. А. Шахматов называл и еще один признак: «формальным их отличием является возможность быть замененными полным предложением» [(1920) 2001: 265].

Л.Н. Иорданская и И.А. Мельчук указывают четыре признака вводных слов (в их терминологии «вводных выражений», для которых они используют символ Advввод): «1) с семантической точки зрения, сфера действия оборота Advввод включает все высказывание; 2) с коммуникативной точки зрения, смысл, который выражен посредством Advввод, представляет собой информацию второго плана; 3) с точки зрения линейной организации высказывания, Advввод может занимать любую позицию в предложении; 4) с просодической точки зрения, Advввод имеет специальную интонацию и может отделяться от остальной части предложения паузами» [2007: 372].

В русской синтаксической традиции вводные слова принято рассматривать в связи с предикативными единицами. Так, Д.Н. Овсянико-Куликовский считал, что вводные слова - это неполные предложения: вводные слова составляют «как 
бы часть неоконченного, недоговоренного предложения, или, наоборот, ... результат сокращения некогда полного предложения, от которого осталась лишь та или другая часть» [1912: 297]. Ту же точку зрения отстаивал А.А. Шахматов [2001: 265]. В. В. Виноградов указал два направления образования класса вводных слов: «Многие из модальных слов, действительно, произошли из вставных предложений. На многих из них еще и теперь лежит отпечаток этого их происхождения. Но многие из модальных слов и частиц возникли и другим путем, например из наречий. Чем бы они раньше ни были, в современном языке они образуют одну грамматическую категорию» [(1947) 2000: 598].

Для русских лексем с модусной семантикой возможны разные синтаксические позиции. Модусные лексемы могут быть частью сложноподчиненного предложения с придаточным изъяснительным (рамочная позиция), входить в состав сказуемого или занимать позиции других членов предложения (внутрисинтаксическая позиция), быть вводным словом (парентетическая, внешнесинтаксическая позиция), выступать в качестве ответной реплики (диалогическая позиция). Разграничение вводной и внутрисинтаксической позиций связано со степенью присутствия модуса в семантике словоформы; в некоторых случаях от этого зависит и квалификация падежа. Так, по мне во вводной позиции (1) относят к Дат. п. (или к «наречному выражению»), а по мне во внутрисинтаксической позиции либо к Дат. п. (2), либо к Предл. п. (3) в зависимости от того, каким членом предложения является словоформа. Примеры: (1) По мне, в стихах все быть должно некстати (Ахматова); (2) Я иду потому, что эта жизнь, которую я веду здесь, эта жизнь - не по мне! (Л.Н. Толстой); (3) Любезный сын, по мне наследник ты один! (Крылов). Первый пример - бесспорно вводная позиция и Дат. п. (я считаю.., по моему мнению); второй - позиция предиката (Дат. п., но для 3-го лица - Предл. п.: не по нем), в рамках которого соединяется и модусная семантика (я считаю) и диктальная (не могу жить этой жизнью), третий - собственно диктальная - Предл. п. (мой наследник, наследник после меня; по мне во временном значении). Но если допустить, что у Льва был не один львенок-сын, то третий пример можно прочесть и по первому варианту: «я считаю, что только ты мой наследник). В этом случае по мне окажется формой Дат. п.

В грамматических описаниях истории русского литературного языка XIX в. было отмечено параллельное употребление «модальных» лексем во вводной позиции и в сложноподчиненном предложении [Очерки... 1964]. Периодом активного формирования в русском языке вводно-модальных слов как особого лексико-грамматического разряда называют XVIII-XIX вв. За два с лишним века произошла «специализация» модусных лексем: одни из них закрепились во вводной позиции и - как следствие - в позиции ответной реплики (по-видимому, наверное, конечно), другие - сохранили возможность употребления в рамочной и внутрисинтаксической позициях (очевидно, вероятно, кажется, разумеется) (см. также об этом [Кузнецова 2017]).

Материалы НКРЯ позволяют проследить динамику в соотношении вводных слов и рамочных союзных конструкций. По данным основного корпуса НКРЯ 
в период с 1800 по 1870 гг. для очевидно соотношение рамочной (перед союзом что) и вводной позиций составляет 1:2. В период с 1900 по 1970 гг. количество употреблений слова очевидно во вводной позиции значительно увеличивается и соотношение вхождений по каждой из этих позиций становится 1:5 в пользу вводности. Изменяется соотношение вводной и внутрисинтаксической позиций для отыменных модальных слов - оно также изменяется в пользу вводности. При этом и в XXI в. для многих лексем сохраняется выбор позиции: он зависит от точки зрения говорящего (субъектной перспективы текста), что непосредственно связано с принадлежностью текста к определенному стилю и жанру.

В многомерном и многосубъектном целом художественного текста вводные слова могут принадлежать разным субъектам сознания и речи (автору, рассказчику, персонажу). При интерпретации вводных слов в третьеличном нарративе необходимо установить «владельца модуса», т.е. того, на чью точку зрения указывает вводное слово. Так, глагол казаться может указывать на точку зрения героя, a) с которой повествователь полностью солидаризируется («Невеста» А. П. Чехова), б) от которой повествователь дистанцируется («Дуэль» А. П. Чехова, начало 2-ой главы). Особую функцию выполняют вводные слова (в том числе казалось) в жанре киносценариев: киносценарий пишется с установкой на приоритет визуальной семантики, т.е. репродуктивного регистра речи, а вводные слова принадлежат, в основном, ментальному и речевому модусам. Следовательно, наличие вводных слов за пределами реплик персонажей указывает на присутствие в киносценарии рассказчика. Наличие вводных слов сближает киносценарий с художественной прозой, хотя понятно, что при отсутствии «голоса за кадром» в фильме вводные слова остаются только в тексте киносценария; см., например, фрагмент из киносценария «Долгая счастливая жизнь» Г. Шпаликова: Странен был переход от созерияания жизни конца ХІХ века, которая вызывала у многих, даже молодых зрителей определенное сопереживание, в эти совершенно иные заботы и интересы, которые, казалось, стали главной целью и задачей вечера: танщевать, разговаривать, завязывать знакомства, искать кого-то в толпе, радоваться происходящему здесь. Весь этот фрагмент - дань художественной прозе, поскольку рассказчика в поставленном Шпаликовым фильме нет. Вводное слово, принадлежащее повествователю («субъекту сознания»), сближает рассказчика и героя, но не соединяет их точки зрения полностью. Мысли автора и героев могли бы воплотиться в слова, и вводные слова были бы произнесены, но этого в фильме нет. Субъективное восприятие действительности Шпаликов-режиссер стремится передать другими средствами.

Вводные слова в художественной прозе маркируют переход от внешнего описания к внутренней мотивировке: По дачной платформе взад и вперед прогуливалась парочка недавно поженившихся супругов. Он держал ее за талию, а она жалась к нему, и оба были счастливы. Из-за облачных обрывков глядела на них луна и хмурилась: вероятно, ей было завидно и досадно на свое скучное, никому не нужное девство («Дачники» А. П. Чехова); от одной субъектной сферы к другой: Тетке казалось, что и с нею случится то же самое, то есть что и она 
вот так, неизвестно отчего, закроет глаза... По-видимому, такие же мысли бродили и в голове Федора Тимофеича. Никогда раньше старый кот не был так угрюм и мрачен, как теперь («Каштанка» А. П. Чехова). Переход от рамочной позиции (сложного предложения) к парентетической указывает на переход от косвенной речи к несобственно-прямой: Анне Акимовне казалось, что Пименов после вчерашнего презирает ее как филантропку, но очарован ею как женщиной. Она смотрела на него и находила, что он держится очень мило и одет прилично. Правда, у сюртука немного рукава коротки и, кажется, талия высокая и брюки не модные, не широкие, но зато галстук повязан со вкусом и небрежно, и не так ярок, как у других. И, по-видимому, он добродушный человек, так как покорно кушает все, что кладет ему на тарелку тетушка («Бабье царство» А.П. Чехова).

2. Особый аспект исследования - онтолингвистический. Анализ диалога взрослых с маленькими детьми позволил установить время появления вводно-модальных слов в речи, выявить их начальный репертуар, оценить частотность использования и описать функции, с которыми они используются обоими партнерами (см. подробнее [Казаковская 2016]) $)^{1}$. Мы обнаружили, что диалогическая ситуация, в которой осуществляется начальное усвоение языка и происходит категоризация эпистемической семантики, «провоцирует» появление редуцированных маркеров модуса, свойственных диалогу. Ими являются ментальные модусные рамки в варианте слов-эгоцентриков.

Исследование показало существенное влияние на этот процесс так наз. модального инпута (речи взрослого, обращенной к ребенку и содержащей соответствующие маркеры) - на формирование состава и функций вводно-модальных слов. Роль инпута заключается в том, что маркеры, обладающие высокой эпистемической силой и частотностью в речи взрослого, имеют шанс попасть (первыми) в речь ребенка. Существенными здесь оказываются и такие элементы диалогической техники, как модусные вопросы взрослого [Казаковская 2019: 252-268].

Ранними функциями вводно-модальных слов в детской речи являются их первичные - собственно эпистемические - функции, а именно выражение уверенности / неуверенности в сообщаемом. Вторичные функции, связанные с нейтрализацией основного значения в пользу подчеркивания той или иной ипостаси

${ }^{1}$ Объем аудио- и видеозаписей составил около 250 часов звучащей речи. Авторы сердечно благодарят коллег и сотрудников, принимавших участие в создании и обработке (CHILDES) корпуса данных: Т. В. Пранову, М. Д. Воейкову, Н. В. Гагарину, М.Б. Елисееву, Е. А. Офицерову, К. А. Иванову, И. В. Яковлеву, М. И. Аккузину и Е.К. Лимбах. Помимо записей спонтанной речи, использовались дневниковые наблюдения родителей, а также результаты экспериментов, направленных на определение понимания детьми эпистемической силы модальных маркеров [Овчинникова, Угланова, Краузе 1999] и выявление частотности их использования в устном монологе [Седов 2004]. Учтены записи коммуникативного взаимодействия взрослых и детей в семье с низким социально-экономическим статусом [Казаковская 2017] и данные разноструктурных языков [Kazakovskaya, Argus 2016; Kazakovskaya, Argus, Uziel-Karl 2018]. 
говорящего, начинают развиваться позже, в среднем после 4 лет. Об этом свидетельствуют дневниковые наблюдения родителей [Там же: 159-165]. При этом во всех доступных нам русских лонгитюдных корпусах данных, как и в ряде разноструктурных языков, изученных в этом отношении [Kazakovskaya et al. 2018], эпистемическое маркирование начиналось с экспликации неуверенности (в другой терминологии, проблематической достоверности). Первыми самостоятельно и уместно использованными маркерами были наверно(е), может (быть), по-моему). Вводно-модальные слова с семантикой неуверенности в достоверности сообщаемого лидировали по разнообразию репертуара и частотности использования в речи. Основные тенденции эпистемического маркирования в ранней детской речи заключались в появлении новых средств выражения и в расширении диктумных ситуаций - объективных пропозиций, по отношению к которым ребенок выражал модальную оценку и свою рефлексию.

Привлечение к исследованию детских текстов - устных и письменных нарративов - представляется нам перспективным, поскольку такой материал позволяет в известном смысле «вывести за скобки» фактор инпута. Так, анализ сочинений школьников показал, что вводные компоненты употребляются детьми с разной степенью частоты (см. подробнее [Казаковская, Гаврилова 2019]). Например, одном из «срезов» сочинений 11-классников, обучающихся по программе социально-экономического профиля, вводные слова маркировали до $30 \%$ предложений. При этом наиболее частотными в работах оказались вводно-текстовые и вводно-модальные слова. Первые использовались для обозначения места высказывания в линейной последовательности текста (65\%), вторые отражали генезис рассуждений и эпистемическую оценку пропозиционального содержания высказывания (30\%). Доля вводно-авторских и вводно-эмоциональных компонентов была невелика - 5 \% (кумулятивно). Рамочные союзные конструкции (так наз. квазисложные предложения) типа Я считаю/думаю, что...; Можно сказать, что... встречались в основном в сочинениях-рассуждениях. Таким образом, употребляя различные средства модуса, пишущие выступили (обнаружили себя) в двух ипостасях - автора собственного текста (что ожидаемо) и автора эпистемической (вероятностной) оценки.

Анализируя причины и условия экспликации средств модуса в детском нарративе, мы обратили внимание на функциональную оправданность появления различных вводных компонентов при создании рассуждения, повествования и описания. Вторым существенным моментом было то, появление вводных компонентов было обусловлено не только стилем и/или жанром создаваемого текста, но и ментальным статусом его автора, полнотой / неполнотой его знаний в отношении определенного положения дел. В частности, при порождении текстов-рассуждений старшеклассники часто пользовались маркерами неуверенности (вероятно, возможно, казалось был) при формировании суждения и тем самым при экспликации собственной точки зрения по отношению к действиям героя повествования (третьего лица), находящегося в ситуации нравственного выбора. Симптоматично, что меньшая категоричность при их оценке соотносилась с принятой в обществе мерой этичности 
ее выражения ${ }^{2}$ В свою очередь, употребление маркеров уверенности (действительно, на самом деле, конечно, несомненно, безусловно, разумеется, бесспорно) чаще всего происходило при солидаризации автора сочинения с мнением автора литературного произведения, обсуждаемого в тексте.

Языковой материал, полученный от восьмиклассников, позволил нам сравнить использование вводных компонентов не только в разных формах речи - письменной и устной, но и в разных типах речи - описании, повествовании и рассуждении. Описания (были предложены картина с историческим сюжетом, сюжетная фотография и портрет) влекли за собой в основном использование вводно-модальных маркеров неуверенности (возможно, наверное, видимо, похоже и др.), что не зависело от формы речи - письменной или устной, тогда как в рассуждениях использовались маркеры уверенности и рамочные союзные конструкции Я думаю/ считаю, (что)... Небезынтересным кажется и то, что при порождении устного нарратива слабо успевающие школьники пользовались ими именно как «рамками», которые помогали в момент их произнесения «додумать» и вербализовать выска-

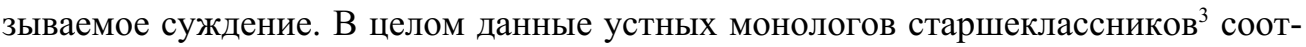
носились с результатами письменных работ.

Наконец, в рамках проводимого исследования нам показалось целесообразным провести небольшой опрос, направленный на выяснение отношения этих же школьников к вводным словам. Таким образом вместе с данными о метаязыковой рефлексии мы рассчитывали получить косвенные свидетельства о функциональном потенциале этих конструкций в речи современных подростков. С этой целью информантам было предложено оценить степень обязательности («нужности») вводных компонентов ${ }^{4}$ в учебниках будущего: оставить нужное (вычеркнуть ненужное) и мотивировать свое решение. Приведем основные результаты анализа интроспективных суждений.

Во-первых, восьмиклассники протестовали против «выбрасывания» вводных слов из учебников и «отказа от» них в речи: «без них наша речь обесцветится» (А.Е.), «вводные слова - это важная часть текста», «каждое слово можно применить в каком-либо случае» (А.К.), «Мне кажется, что без этих слов наша речь невозможна» (А. П.). Особый протест вызвала идея отказаться от вводных слов, которые «помогают выразить эмоциональность»: «без этих слов человек не проживет и не сможет описывать свои чувства» (Д. А.), «вводные слова, которые выражают чувство говорящего особенно важны» (А. Д.).

Во-вторых, дети хорошо чувствовали выход слов из активного запаса («есть современные слова и устаревшие» (А. К. $)^{5}$ ) и/или их книжность: «Я бы удалил те, которые я не использую, то есть очень старые ... чай, надеюсь, полагаю (В. Д.); «дескать,

2 Подобную некатегоричность суждений продемонстрировали восьмиклассники в устных монологах при описании внешности человека по фотографии.

${ }^{3}$ Объем расшифрованных монологов (аудиозапись) составил более 500 фраз.

${ }^{4}$ K анкете прилагался полный список вводных слов и конструкций.

${ }^{5}$ Орфографические и пунктуационные особенности ответов сохранены; личные данные информантов зашифрованы. 
мол нужно удалить либо поставить «устаревш.»» (А.К.). Подобные замечания сопровождали подлинно, не ровен час, (не)чего греха таить (В.К.); чего доброго (Д.М.); с позволения сказать, по преданию (А.П.); быть может, надо полагать (Р.Х.); с позволения сказать, скажите на милость, не в укор будь сказано, сказать по чести, заметьте себе, между нами будь сказано. Многие отметили, что русский язык «не стоит на месте и постоянно меняется и преобразовывается (А.Е.), «растет и развивается» (В.К.): «В настоящее время многие конструкции не употребляются, а многие наоборот набирают популярность. Это значит, что русский язык развивается» (Н.С.), «Учебники составляют для нового поколения, поэтому эти слова им будут чужды, поэтому включать их в учебную программу не имеет смысла» (Д. С.).

В-третьих, многие анкеты содержали указание на частотность и употребительность вводных компонентов: «На самом деле я бы ничего не убирал из этого списка, поскольку они мелькают в каждом втором предложении» (И.К.), «наш словарный запас на половину состоит из вводных слов» (Т. Л.). Наиболее употребительными сегодняшние подростки считают к счастью, к сожалению; конечно, наверное, очевидно, безусловно; итак, значит; говорят, по словам...; бывает: «самые распространенные и ходовые ...ммжет быть, видимо, вероятно, возможно», по-моему, так сказать, честно говоря; по правде. Более того, некоторые пытались вспомнить, в устной или письменной речи и в какой именно ситуации они используют такие слова и выражения: «...с друзьями использую разумеется, самое большее, по крайней мере» (В.Д.), «Чаще всего на уроке, при написании каких-либо письменных работ я использую следовательно, иными словами, видите, представьте себе, по словам, очевидно» (Н.С.). В отдельных работах присутствовал намек на понимание возрастных особенностей речи: «На самом деле все вводные слова играют свою роль. Я не могу вот так сказать какие убрать, какие оставить. Сейчас в своем возрасте мы используем одни вводные слова, а когда вырастем будем использовать другие» (Т. Л.).

Наконец, осознавая использование вводных слов как примету «хорошей, красивой и удобной речи» («с их употреблением проще общаться» (В.К.)), юные носители языка рекомендовали тем не менее умеренность в их употреблении: «Умных слов должно быть в меру, иначе наша речь превратится в бессвязный бред (А.Е.) и советовали объединить «близкие по смыслу» группы (И.К.). Например, было предложено соединить «выражение чувств» и «экспрессивность высказывания», «связь мыслей, последовательность изложения» и «указание на приемы и способы оформления мыслей» (В.К., Н. С.). Некоторые советовали отказаться от «указания на оценку меры того, о чем говорится: «Я считаю, это вполне очевидные вещи (последнее слово зачеркнуто. - Прим. наше.) и слова» (А. Д.) Самое радикальное предложение последовало от ребенка, в анкете которого зафиксировано наибольшее количество ошибок: «Передо мною список вводных слов он очень большой. Мне кажется в нем много лишних слов и их можно убрать».

Одиннадцатиклассники в 60 \% случаев высказались за «нужность» всех вводных слов и конструкций, кроме устаревших и просторечных. Ряд анкет содержал разного рода редакции списка. Приведем два наиболее типичных комментария: «Я считаю, 
что в русском языке не нужно убирать вводные слова и конструкции, так как: они придают языку богатство речи; с помощью вводных слов легче донести до собеседника информацию, и, наоборот, легче его понять; вводные слова позволяют уточнить то, что мы хотим сказать; с их помощью мы можем привлечь внимание; они помогают связывать и не терять мысли» (О. М.); «С одной стороны, список вводных слов нужно увеличивать, добавлять сложные вводные слова и словосочетания, которые, может быть, ребенок не слышал. Они могут попасться на экзамене и, если их не знать, стать причиной потери баллов. К тому же, пополнение словарного запаса всегда идет на пользу, а вводные слова делают речь выразительнее. С другой стороны, такие сложные вводные слова (устаревшие, малознакомые), как чай, дескать, помилуйте, уже почти не употребляются, им на смену приходят новые, более современные, поэтому вскоре, может быть, их можно будет убрать из сборника» (У.Ш.).

3. Представленные наблюдения и обобщения призваны показать перспективность соединения системно-языкового (грамматического), текстового и онтолингвистического подходов при описании столь сложных лексико-грамматических объектов, которыми являются вводные слова: сочетание подходов позволяет выявить их свойства.

Вводные слова занимают особое место в языковой системе - между полнознаменательными частями речи и служебными, между лексемами и синтаксемами, между словами и предложениями. Их модусная семантика принадлежит трем модусам: ментальному, эмотивному и речевому. Она может реализоваться в различных синтаксических позициях, однако наиболее важными и связанными друг с другом являются рамочная и вводная позиции. Переход отдельных словоформ разных частей речи в класс вводных слов свидетельствует об их выходе из разряда дескриптивных единиц номинации и приобретении ими статуса дискурсивных эгоцентрических элементов.

Данные речевого онтогенеза указывают на то, что вводно-модальные слова самые ранние экспликаторы модусной и субъективно-модальной семантики. Ранний онтогенез позволяет судить и об их прототипичности (изосемичности) в сфере средств выражения точки зрения говорящего в диалогическом режиме. Очередность усвоения средств выражения модальности в онтогенезе может коррелировать с их диахроническим развитием и тем самым быть связанной с грамматикализацией этой категории в русском языке. Например, известно, что вводно-модальные видимо и возможно начинают использоваться позже, чем наверно(е) [Гатинская 2007]. Однако наша гипотеза нуждается в проверке.

Более позднее (по сравнению с деонтической и динамической разновидностями) усвоение эпистемической модальности объясняется ее когнитивной сложностью - вербализацией субъективного начала, позиции говорящего. Мы склонны предположить, что когнитивные факторы существенны и в позднем речевом онтогенезе, однако их действие проявляется на ином уровне, в частности при создании письменного текста. Так, бо́льшая когнитивная зрелость одиннадцатиклассников позволяет им лучше чувствовать позицию автора и таким образом учитывать 
точку зрения Другого, что, в свою очередь, увеличивает частотность использования вводно-модальных слов с семантикой уверенности. В раннем онтогенезе, заметим, это более поздние и менее употребительные эгоцентрики. На разнообразие эпистемического и в целом субъективно-модального репертуара школьника способны влиять гуманитарный склад личности и уровень развития коммуникативной компетенции. Но повторяемость заданий и многократность создания текста одного стиля и жанра приводят, по нашим данным, к обеднению репертуара и своего рода шаблонизации в употреблении вводных слов выпускниками, нацеленными на сдачу экзамена установленного формата.

Исследование показывает, что использование вводных компонентов свойственно детям, подросткам, взрослым носителям языка в различной степени. По данным раннего и позднего онтогенеза, они отсутствовали только в речи ребенка из семьи с низким социально-экономическим статусом, а отказаться от них в «учебнике будущего» предложил плохо успевающий ученик. С возрастом функциональный диапазон вводно-модальных слов расширяется. Они попадают в письменную речь, а кроме того начинают осознаваться как необходимый элемент повседневного дискурса. В текстах мастеров художественного слова вводные слова не только субъективируют информацию, заключенную в отдельном предложении, но и маркируют место этого предложения в субъектной организации всего текста. В нарративном тексте их эгоцентрическая сущность используется автором для умножения субъектов модуса, для создания текстовой полифонии. В третьеличном нарративе они обнаруживают большую или меньшую дистанцию между автором и героем, маркируют переход от одной точки зрения к другой. Функционально-грамматическая характеристика вводных слов требует учета межуровневого взаимодействия, соединения лексической семантики с синтаксисом предложения и анализом текста.

\section{Литература}

Виноградов В.В. Русский язык (Грамматическое учение о слове). М.: Русский язык, 2000. $720 \mathrm{c.}$

Гатинская Н.В. Модально-оценочные слова в современном и историческом контексте // Вестник РУДН. Сер. Вопросы образования: языки и специальность. № 1. C. 17-24.

Золотова Г.А., Онипенко Н.К., Сидорова М. Ю. Коммуникативная грамматика русского языка. М.: ИРЯ РАН, 2004. 544 с.

Иорданская Л.Н., Мельчук И.А. Смысл и сочетаемость в словаре. М.: Языки славянских культур, 2007. 665 с.

Казаковская В. В. Эпистемическая модальность в русской детской речи // Грамматические процессы в синхронии и диахронии. Труды ИРЯ РАН им. В.В. Виноградова. Вып. 10. М.: ИРЯ РАН, 2016. С. 104-119.

Казаковская В. В. Языковое и когнитивное в усвоении эпистемической модальности // Acta Linguistica Petropolitana. Труды Института лингвистических исследований. Т. 13. Ч. 3. СПб.: ИЛИ РАН, 2017. С. 542-575. 
Казаковская B. В. Вопрос и ответ в диалоге «взрослый - ребенок»: Психолингвистический аспект. М.: Либроком, 2019. 448 с.

Казаковская В.В., Гаврилова М.В. Вводность и тинейджер (к проблеме точки зрения) // Современная онтолингвистика: Проблемы, методы, открытия. Иваново: ЛИСТОС, 302-307.

Кузнецова С.М. Системно-синтаксическое описание отадъективных модусных транспозитивов на -о. Автореф. дис. ... канд. филол. наук. М.: МГУ, 2017. 23 с.

Овсянико-Куликовский Д. Н. Синтаксис русского языка. Изд. 2-е. СПб.: Изд. И. Л. Овсянико-Куликовский, 1912: 322 с.

Онипенко Н.К. Модель субъектной перспективы и проблема классификации эгоцентрических элементов // Проблемы функциональной грамматики: Принцип естественной классификации. М.: Языки славянских культур, 2013. С. 92-121.

Очерки по исторической грамматике русского литературного языка XIX в. T. 5. Изменения в строе сложноподчиненного предложения. М.: Наука, 1964. 264 с.

Падучева E. В. Модальность. Материалы для проекта корпусного описания русской грамматики (http://rusgram.ru). На правах рукописи. М., 2016.

Шахматов А. А. Синтаксис русского языка. М.: УРСС, 2001. 623 с.

Kazakovskaya V.V., Argus R. Acquisition of epistemic marking in Estonian and Russia // Estonian Papers in Applied Linguistics. 2016. №12. P. 57-80. http://doi. org/10.5128/ERYa12.04

Kazakovskaya V., Argus R., Uziel-Karl S. 2018.The Early Expression of (Un)certainty in Typologically Different Languages: Evidence from Russian, Estonian and Hebrew // Philologia Estonica. On Language and Culture. №3. P. 93-130. https://doi.org/10.22 601/ PET.2018.03.04

\author{
Viktoria V. Kazakovskaya \\ Institute for linguistic studies RAS \\ (Saint Petersburg, Russia) \\ victory805@mail.ru \\ Nadezhda K. Onipenko
}

Vinogradov Russian Language Institute of the Russian Academy of Sciences

(Moscow, Russia)

onipenko_n@mail.ru

\title{
FUNCTIONALITY OF PARENTHETICAL MODAL WORDS IN THE SPEECH OF ADULTS AND CHILDREN
}

The object of the study is the function of parenthetical modal words in terms of the system of language (synchrony vs. diachrony), in textual discourse, and ontolinguistics. Parenthetical words are interpreted in connection with the concept of modus and the subjective text perspective model. A condition for the formation of 
parenthetical words is the appearance of an egocentric component in the semantics of the lexeme. The egocentric nature of these units is manifested in the restriction of the personal paradigm and the consolidation of particular variants of a subjective paradigm for a given lexical unit; their discursive essence is manifested in the possibility of using them as connectors and in coordination with them. Different syntactic positions words with epistemic semantics and the textual functions of parenthetical words in third-person narratives are considered. The paper is based on materials of the NCRL (artistic narrative), as well as data of speech ontogenesis obtained via longitudinal and cross-sectional methods. The materials presented include decoded and morphologically tagged (in accordance with CHILDES) audio and video recordings of early «adult - child» dialogue, as well as data on the oral and written speech of Russian teenagers, supplemented by questionnaires reflecting their attitude to the parenthetical words.

Keywords: syntax, communicative grammar, ontolinguistics, parenthetical modal words, modus, egocentric vocabulary, parenthetical position.

\section{References}

Gatinskaya N.V. Modal'no-ocenochnye slova v sovremennom i istoricheskom kontekste. Vestnik RUDN. Ser. Voprosy obrazovaniya: yazyki i special'nost', 2007, no. 1, pp. 17-24. (In Russ.)

Iordanskaya L.N., Mel'chuk I.A. Smysl i sochetaemost'v slovare. Moscow, «Yazyki slavyanskix kul'tur» Publ., 2007. 665 p. (In Russ.)

Kazakovskaya V.V. Epistemicheskaya modal'nost' v russkoj detskoj rechi. Grammaticheskie processy $v$ sinxronii i diaxronii. Trudy IRYa RAN im. V. V. Vinogradova. Vyp. 10. Moskow, IRYa RAN, 2016, pp. 104-119. (In Russ.)

Kazakovskaya V. V. Yazykovoe i kognitivnoe v usvoenii epistemicheskoj modal'nosti. Acta Linguistica Petropolitana. Trudy Instituta lingvisticheskix issledovanij, v. 13, part 3, St. Petersburg, ILI RAN, 2017, pp. 542-575. (In Russ.)

Kazakovskaya V.V. Vopros $i$ otvet $v$ dialoge «vzroslyj - rebenok»: Psixolingvisticheskij aspekt. Moscow, Librokom, 2019. 448 p. (In Russ.)

Kazakovskaya V.V., Argus R. Acquisition of epistemic marking in Estonian and Russian. Estonian Papers in Applied Linguistics, 2016, no. 12, pp. 57-80. http://doi. org/10.5128/ERYa12.04

Kazakovskaya V., Argus R., Uziel-Karl S. The Early Expression of (Un)certainty in Typologically Different Languages: Evidence from Russian, Estonian and Hebrew. Philologia Estonica, 2018, no. 3. https://doi.org/10.22 601/PET.2018.03.04

Kazakovskaya V. V., Gavrilova M.V. Vvodnost' i tinejdzher (k probleme tochki zreniya). Sovremennaya ontolingvistika: Problemy, metody, otkrytiya. Ivanovo, LISTOS, pp. 302-307. (In Russ.)

Kuznetsova S.M. Sistemno-sintaksicheskoe opisanie otad"ektivnyxmodusnyx transpozitivov na -o. Avtoref. dis. ... kand. filol. nauk. Moscow, MGU, 201723 p. (In Russ.) 
Ovsyaniko-Kulikovskij D. N. Sintaksis russkogo yazyka. Izd. 2-e. St. Petersburg, Izd. I. L. Ovsyaniko-Kulikovskoj, 1912. 322 p. (In Russ.)

Onipenko N.K. Model' sub "ektnoj perspektivy i problema klassifikacii egocentricheskix elementov. Problemy funkcional'noj grammatiki: Princip estestvennoj klassifikacii. Moscow, «Yazyki slavyanskix kul'tur» Publ., 2013, pp. 92-121. (In Russ.)

Ocherki po istoricheskoj grammatike russkogo literaturnogo yazyka XIX v. T. 5. Izmeneniya $v$ stroe slozhnopodchinennogo predlozheniya. Moscow, «Nauka» Publ., 1964. 264 p. (In Russ.)

Paducheva E. V. Modal'nost'. Materialy dlya proekta korpusnogo opisaniya russkoj grammatiki (http://rusgram.ru). Na pravax rukopisi. Moscow, 2016. (In Russ.)

Shaxmatov A. A. Sintaksis russkogo yazyka. Moscow, URSS, 2001. 623 p. (In Russ.)

Vinogradov V.V. Russkij yazyk (Grammaticheskoeuchenie o slove). Moscow, «Russkij yazyk» Publ., 2000. 720 s. (In Russ.)

Zolotova G.A., Onipenko N.K., Sidorova M.Yu. Kommunikativnaya grammatika russkogo yazyka. Moscow, IRYa RAN, 2004. 544 p. (In Russ.) 